\title{
Characterizing landscape changes in central Rondônia using Landsat TM imagery
}

\author{
D. S. AlveS, J. L. G. PEREIRA, C. L. DE SOUSA, J. V. SOARES \\ and F. YAMAGUCHI \\ Instituto Nacional de Pesquisas Espaciais (INPE), Av. dos Astronautas 1758, \\ C.P. 515, CEP 12227-010, São José dos Campos, SP, Brazil: \\ e-mail: dalves@dpi.inpe.br
}

(Received 7 July 1998; in final form 5 February 1999)

\begin{abstract}
An analysis of landscape changes in a region of pioneer settlements in central Rondônia, western Brazilian Amazon, was derived from Landsat TM data. Total deforested area increased from $206 \times 10^{3}$ ha in 1977 , to $565 \times 10^{3}$ ha in 1985 and to $1210 \times 10^{3}$ ha, or $35.5 \%$ of the region, in 1995 . Eighty-one per cent of the total 1995 deforestation had occurred in regions within $12.5 \mathrm{~km}$ from areas of pioneer colonization deforested by 1977. Deforested area exceeded $79 \%$ in regions within $12.5 \mathrm{~km}$ from the region's first road.
\end{abstract}

\section{Introduction}

The forests of Brazilian Amazon have undergone important changes over the past three decades due to human occupation. Such process has resulted in the deforestation of at least 52 million hectares (ha) by 1996 (Instituto Nacional de Pesquisas Espaciais (INPE) 1998), with significant loss of forest in the states of Maranhão, Mato Grosso, Pará, and Rondônia (Tardin et al. 1980, INPE 1998, Alves et al. 1998a).

This work presents a simplified analysis of landscape changes in an area of high deforestation rates in the state of Rondônia. A deforestation map was derived from Landsat Thematic Mapper (TM) imagery for years 1985 and 1995, and the evolution of the deforested area was evaluated in the proximity of areas of pioneer colonization and major roads. The aim of this analysis is to contribute to a better understanding of the deforestation process, by assessing some of the effects of long-term occupation.

\section{Study area}

The study area is located in the western part of the Brazilian Amazon, including parts of the municipios of Ariquemes, Cacaulândia, Governador Jorge Teixeira, Jamari, Jarú, Ji-Paraná, Machadinho d'Oeste, Ministro Andreazza, Ouro Preto do Oeste, Presidente Médici, Rio Crespo, Theobroma, and Vale do Paraíso, in the state of Rondônia, and Aripuanã, in the state of Mato Grosso (MT). Its limits correspond to the common area between the 1985 and 1995 TM images ( path/row $=231 / 067$ ) used in the analysis.

Human occupation in the study area has increased considerably during the last

International Journal of Remote Sensing

ISSN 0143-1161 print/ISSN 1366-5901 online (C) 1999 Taylor \& Francis Lid

http://www.tandf.co.uk/JNLS/res.htm

http://www.taylorandfrancis.com/JNLS/res.htm 
three decades, following the opening of federal road BR-364 and the establishment of several pioneer settlements along that road. In the early 1980 s, colonization of more remote areas was initiated, particularly in the region of Machadinho d'Oeste (Instituto Nacional de Colonização e Reforma Agrária (INCRA) 1996). Deforestation rates in the area are among the highest in Brazilian Amazon (Alves et al. 1998a, INPE 1998).

\section{Data and methods}

\subsection{Data}

The deforestation map used in this work was derived from TM images acquired on 22 July 1985 and 3 August 1995. Additional TM images for years 1986, 1988, 1990, 1992 and 1994 were used to elucidate classification ambiguities and evaluate the deforestation map. All TM images were geo-referenced using coordinates acquired on the field by differential GPS equipment. Areas of pioneer deforestation were obtained from a 1977 deforestation map derived from Landsat MSS data by Tardin et al. (1980). Municipal boundaries were provided by Fundação Instituto Brasileiro de Geografia e Estatistica (FIBGE ND 1994). Ground data were collected at the time of six visits to the study area, from May 1995 to December 1997.

\subsection{Methods}

Deforested areas were classified initially by detecting pixels that exceeded threshold values on the mid-infrared channel (TM band 5) of the 1985 and 1995 images as described by Alves et al. (1998b). Classification errors were detected by visual inspection of the image time-series and corrected by interactive adding and subtracting of pixel masks. The 1985 and 1995 classifications were combined into a single deforestation map that is presented in this Letter. Deforested areas in the map included pastures, annual and perennial crops, burned areas and secondary vegetation.

The final step of the analysis consisted in determining the deforested area in each municipio, and the fraction of deforestation in the proximity of the pioneer deforestation and the major roads. This was done by using map-intersecting operations and building buffers around areas of pioneer deforestation and major roads. Percent cleared was determined as deforested area relative to area as in Frohn et al. (1996).

\section{Results and discussion}

The deforestation map for years 1985 and 1995 is shown in figure 1. The Kappa coefficient of agreement $(\kappa)$ (Hudson and Ramm 1987) was estimated for this map by comparing it with randomly selected areas taken from the image time-series. An estimate of $\kappa=0.89\left(\sigma_{k}^{2}=10^{-6}, N=35214\right)$ was obtained, indicating an excellent degree of accuracy of the final map.

Total deforestation increased from $205.8 \times 10^{3}$ ha in 1977 , to $564.9 \times 10^{3}$ ha in 1985 and to $1210 \times 10^{3}$ ha in 1995 , representing $35.5 \%$ of the study area by 1995 . The deforested area in each municipio is presented in table 1. Ariquemes, Jarú, Ji-Paraná, Ouro Preto do Oeste, Theobroma, and Vale do Paraíso jointly contributed to $92 \%, 82 \%$ and $70 \%$ of total deforestation, respectively, in 1977,1985 and 1995 . These municipios are located in a region where pioneer settlement projects were established in the early 1970s (INCRA 1996), following the building of federal road BR364. These results show that most deforestation has occurred in the regions of pioneer settlements and in the proximity of the BR364 road. At the same time, the 

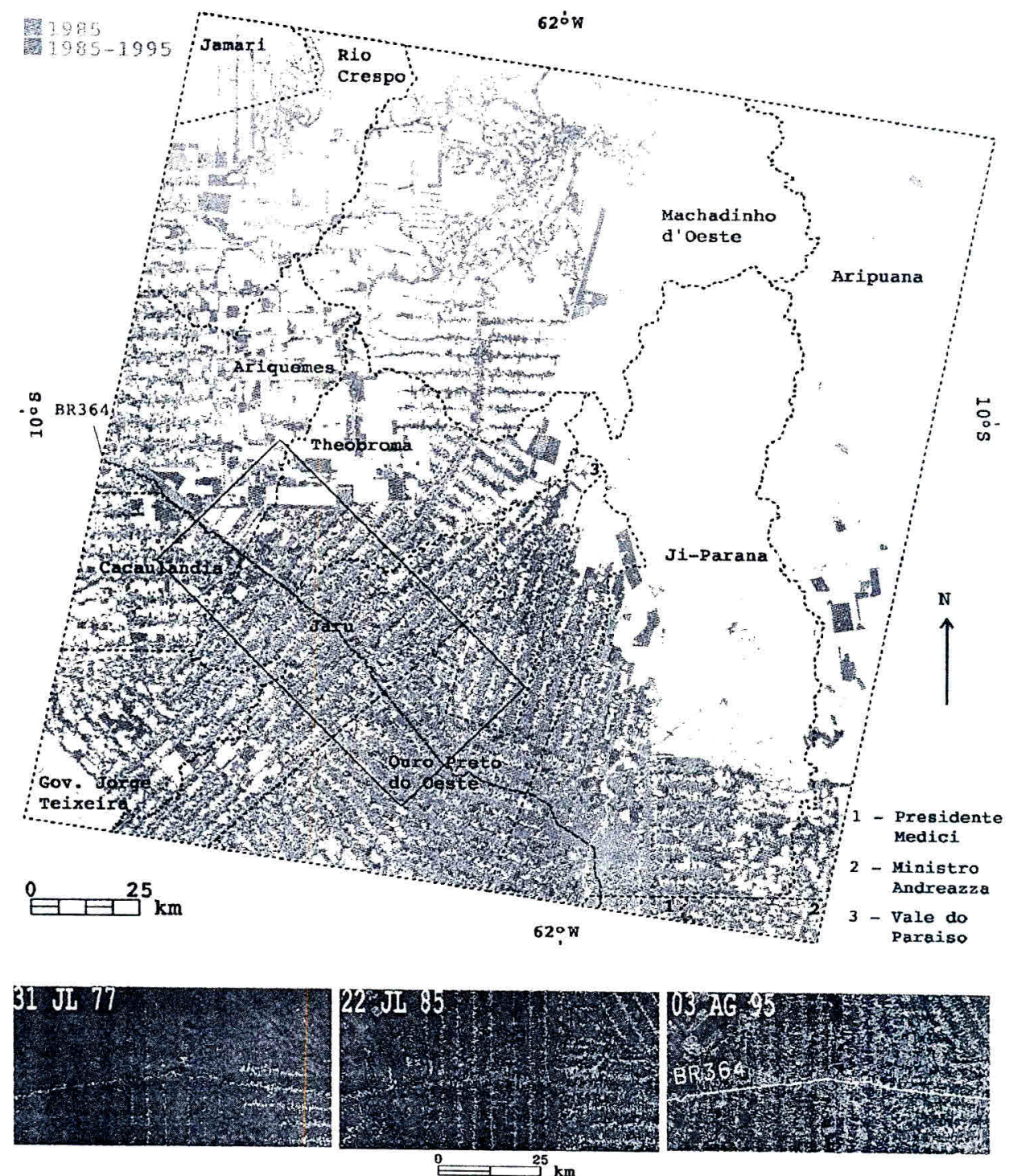

Figure 1. Deforestation map showing areas deforested by 1985 and in the 1985-1995 period (top). A region of pioneer settlements is delimited in red and is shown below on color composites of 1977, 1985 and 1995 MSS and TM images. The loss of forest during the period of study can be observed on the images, where forest appears in red and deforested areas are mostly grey and blue. Federal road BR364 is also shown.

percent contribution of Machadinho d'Oeste and Rio Crespo to total deforestation increased seven-fold from 1977 to 1995 , following the establishment of settlement projects in that region in the early 1980s (INCRA 1996).

In 1995, percent cleared exceeded $46 \%$ in Ariquemes, Cacaulândia, Governador Jorge Teixeira, Jarú, Ministro Andreazza, Ouro Preto do Oeste, Presidente Médici, Theobroma, and Vale do Paraíso (table 1). These results indicate that deforestation is exceeding the primary $50 \%$-limit established by Brazilian federal regulations in 
several areas. This process appears to be more intense in the regions of pioneer settlement, leading to the continuous depletion of forest reserves, that can be observed on time-series of Landsat MSS and TM imagery (figure 1).

The relationship between deforestation and regions of pioneer settlement was investigated further by analysing buffers within $2.5 \mathrm{~km}, 5 \mathrm{~km}, 7.5 \mathrm{~km}, 10 \mathrm{~km}$ and $12.5 \mathrm{~km}$ from the areas deforested by 1977 as mapped by Tardin et al. (1980). Buffers corresponding to $12.5 \mathrm{~km}$ were found to include significant fractions of total deforestation, and are further discussed in this Letter. Ninety-two per cent of the total 1985 deforestation and $81 \%$ of the total 1995 deforestation occurred within $12.5 \mathrm{~km}$ from the areas deforested by 1977 (table 1). In these regions, almost all municipios were deforested by $50 \%$ or more by 1995, with the exceptions of Machadinho d'Oeste, Rio Crespo and Aripuanã (MT), that presented few deforested areas in 1977 (table 1).

Deforestation and percent cleared in buffers within $12.5 \mathrm{~km}$ from the region's major roads were determined and are reported in table 1. Federal road BR364 and the links between Machadinho d'Oeste and BR364 through Jarú (road C603/605) and Ariquemes (roads C65 and C105) were considered in this analysis. Regions within $12.5 \mathrm{~km}$ from these roads accounted for nearly half of total deforestation in 1985 and 1995. Percent cleared in these areas exceeded 50\% in Cacaulândia, Jarú, Ji-Paraná, Ouro Preto d'Oeste, Presidente Médici, Theobroma, and Vale do Paraíso, all areas of pioneer settlement near the BR364 road. In regions within $12.5 \mathrm{~km}$ from BR364, percent cleared increased significantly between 1985 and 1995, reaching 79\% in 1995. In these regions, Jarú, Ji-Paraná, Ouro Preto do Oeste, Presidente Médici, and Theobroma had lost at least $75 \%$ of their forests by 1995 .

The analysis also showed that deforestation has expanded to new areas in Machadinho d'Oeste and Rio Crespo, particularly in regions near roads C603/605, $\mathrm{C} 65$, and $\mathrm{C} 105$. The fraction of total deforestation within $12.5 \mathrm{~km}$ from these roads increased from $14 \%$ to $21 \%$ between 1985 and 1995 . This confirms the diffusion of the deforestation process to more remote areas in Machadinho d'Oeste and Rio Crespo, following the development of new settlements and roads.

\section{Conclusion}

This work reported data on the evolution of the deforestation process between 1977 and 1995 for a region that has undergone important changes during the last three decades. Results were based on a relatively simplified approach that nonetheless showed how landscape changes are causing the continuous forest depletion in the region.

Deforestation and percent cleared were more important in areas of pioneer settlement, where the landscape appeared to be dominated by cattle pastures during the field campaigns. Landscape patterns in such areas suggest that the process of converting small agricultural areas into larger cattle ranches may be occurring over significant regions, contributing to uninterrupted forest clearing. This appears to be a dominant process in some areas, and represents an important topic for further research.

\section{Acknowledgments}

This work was supported by grants from FAPESP (95/2432-5), CNPq (301474/91) and FINEP (0816/95, contrato 6.6.96.0474.00). We are sincerely grateful to Eraldo Matricardi and SEDAM for all their help in Rondônia, and to the Ministry 
of the Army for its support in the air surveys and recovering the history of BR364 construction.

\section{References}

Alvis, D. S., DA Costa. W. M.. Escada, M. I. S., Lopes. E. S. S.. DE SOlzA, R. C. M., and Ortiz, J. D., 1998a. Análise da distribuição espacial das taxas de desflorestamento dos municípios da Amazônia Legal no período 1991-1994. INPE-AMZ-R04/98. Instituto Nacional de Pesquisas Espaciais, Brazil

Alves, D. S., Pereira, J. L. G., Souza, C. L., Soares, J. V., and Yamaguchi, F., 1998 b. Classification of the deforested area in central Rondônia using TM imagery. In Proceedings of the Brazilian Symposium on Remote Sensing, Santos, Brazil. 11-18 September 1998 (São José dos Campos: Instituto Nacional de Pesquisas Espaciais), CDROM.

Frohn, R. C., McGwire. K. C., Dale, V. H., and Estes, J. E., 1996, Using satellite remote sensing analysis to evaluate a socio-economic and ecological model of deforestation in Rondônia, Brazil. International Journal of Remote Sensing, 17, 3233-3255.

Fundação Instituto Brasileiro de Geografia e Estatistica (FIBGE), ND, 1994, Malha Municipal georreferenciada correspondente ao quadro territorial vigente em 31 de dezembro de 1994 (Rio de Janeiro: Fundação Instituto Brasileiro de Geografia e Estatística).

Hudson, W. D., and Ramm, C. W., 1987, Correct formulation of the kappa coefficient of agreement. Photogrammetric Engineering and Remote Sensing, 53, 421-422.

Instituto Nacional de ColonizaÇão e Reforma Agrária (INCRA), 1996, Dossiê-Divisão de Assentamento (Porto Velho: Instituto Nacional de Colonização e Reforma Agrária).

Instituto Nacional de Pesquisas Espaciais (INPE), 1998, INPE atualiza os dados do desflorestamento na Amazônia, de 95 a 97. INPE Notícias, 13, 1-2.

Tardin, A. T., Lee, D. C. L., Santos, R. J. R., Assis, O. R., Barbosa, M. P. S., Moreira. M. L., Pereira, M. T., Silva, D., and Santos Filho, C. P.. 1980, Subprojeto desmatamento: convênio IBDF/CNPq-INPE. INPE-1649-RPE/103. Instituto Nacional de Pesquisas Espaciais, Brazil. 